\title{
Diabetes and obesity during pregnancy alter insulin signalling and glucose transporter expression in maternal skeletal muscle and subcutaneous adipose tissue
}

\author{
Michelle Colomiere ${ }^{1}$, Michael Permezel ${ }^{1}$ and Martha Lappas ${ }^{1,2}$ \\ ${ }^{1}$ Department of Obstetrics and Gynaecology, Mercy Perinatal Research Centre, Mercy Hospital for Women, University of Melbourne, \\ 4th Floor, 163 Studley Road, Heidelberg 3084, Victoria, Australia \\ ${ }^{2}$ Translational Proteomics, Baker IDI, Melbourne, Victoria 3004, Australia \\ (Correspondence should be addressed to M Lappas at Department of Obstetrics and Gynaecology, Mercy Hospital for Women, University of Melbourne; \\ Email: mlappas@unimelb.edu.au)
}

\begin{abstract}
Severe insulin resistance is a defining attribute of gestational diabetes mellitus (GDM). It is postulated that alterations in the insulin-signalling pathway and subsequent glucose disposal are the underlying cause of insulin resistance in patients with GDM. The purpose of this study was to profile the insulin-signalling pathway and intermediates in insulin-sensitive tissues. Subcutaneous adipose tissue and skeletal muscle were collected from normal glucose-tolerant (NGT) and insulin-controlled GDM in both non-obese and obese cohorts ( $n=6-8$ per subgroup). Expression studies of the insulin-signalling pathway were performed using western blotting and quantitative reverse transcription-PCR. This study demonstrated altered mRNA expression of insulin receptor substrate (IRS)-1, IRS-2, glucose transporter (GLUT)-1, GLUT-4 and glycogen synthase kinase (GSK)-3 isoforms genes in adipose tissue in GDM women in comparison to NGT pregnant controls. In skeletal muscle, insulin-controlled GDM was associated with decreased IRS-1, phosphatidylinositol-3-kinase (PI3-K) p85 $\alpha$, GLUT-1 and -4, GSK-3 isoforms and phosphoinositide-dependent kinase-1. Both adipose tissue and skeletal muscle from women with GDM displayed decreased IRS-1 and GLUT-4 and increased PI3-K p85 $\alpha$ protein expression. Both skeletal muscle and adipose tissue from obese women demonstrated lower GLUT-1 and -4 mRNA expression and diminished GLUT-4 protein expression in skeletal muscle only. Collectively, our results suggest that diabetes and obesity during pregnancy cause defects in insulin-signalling transduction in adipose tissue and skeletal muscle and may be the underlying cause of GDM.
\end{abstract}

Journal of Molecular Endocrinology (2010) 44, 213-223

\section{Introduction}

The later part of normal human pregnancy is characterised by maternal hyperinsulinaemia and a progressive decline in insulin sensitivity, an adaptation required for adequate transport of nutrients between mother and foetus (Buchanan \& Xiang 2005). When insulin secretion is inadequate and unable to compensate for the insulin resistance present in pregnancy, gestational diabetes mellitus (GDM) develops. In Australia, 5-8\% of pregnant women develop GDM (Beischer et al. 1996), a maternal complication defined as any degree of glucose intolerance with onset or first recognition during pregnancy (Kuhl 1998). These women have increased risk of type 2 diabetes mellitus (T2DM) and heart disease later in life (Lee et al. 2008), and their offspring have greater incidence of perinatal complications and increased risk of obesity and diabetes in adulthood (Metzger 2007).
Blood glucose levels are regulated by the insulinsignalling pathway. The $\beta$-cells of the pancreas secrete insulin, which binds to the $\beta$-subunit of the insulin receptor (IR- $\beta$ ) resulting in autophosphorylation of its tyrosine residues and consequent tyrosine phosphorylation of downstream insulin receptor substrates (IRS). The activation of IRS substrates allows the recruitment of downstream effectors such as phosphatidylinositol-3-kinase (PI3-K; Pessin \& Saltiel 2000). PI3-K regulates glucose uptake via translocation of glucose transporter (GLUT)-4 from the cytoplasm to the plasma membrane (Czech \& Corvera 1999). A number of other genes have also been implicated in insulin signalling and glucose metabolism in peripheral tissues. These include glycogen synthase kinase (GSK)-3 (Cline et al. 2002, Hojlund et al. 2003, Patel et al. 2008), phosphoinositide-dependent kinase (PDK)-1 (Yamada et al. 2002, Hashimoto et al. 2006, Bayascas et al. 2008), insulin-like 
growth factor-binding protein 1 (IGFBP1; Qiu et al. 2005) and phosphoenolpyruvate carboxykinase (PEPCK; Franckhauser et al. 2006).

There are only a few studies that have investigated endogenous levels of insulin-signalling intermediates in pregnancies complicated by GDM, and these have focused on obese women with GDM (Friedman et al. 1999, Catalano et al. 2002, Tomazic 2002). Nevertheless, these studies have found that GDM is associated with changes in insulin-signalling intermediates in skeletal muscle and adipose tissue and/or adipocytes (Friedman et al. 1999, Catalano et al. 2002, Tomazic 2002). Specifically, reports have demonstrated reduced IRS-1 and increased IRS-2 and PI3-K p $85 \alpha$ protein levels in both skeletal muscle and adipocytes from obese women with GDM in comparison to normal glucosetolerant (NGT) obese pregnant controls (Catalano et al. 2002, Tomazic 2002). Furthermore, GLUT-4 and subsequent glucose uptake is lower in adipose tissue and skeletal muscle in women with GDM (Garvey et al. 1992, 1993).

Maternal obesity is a mounting problem worldwide and is significantly implicated in adverse pregnancy outcomes for both mother and offspring. Obese pregnant women have a three- to tenfold higher risk of diabetes compared to those of normal weight women (Sebire et al. 2001). Previous studies have demonstrated that although mothers can give rise to normal weight offspring, these offspring are still at risk of developing obesity and insulin resistance later in adulthood (Mingrone et al. 2008). Furthermore, the combination of obesity and GDM is thought to compound risk and complications for women during pregnancy. In recently published studies, we have shown that obesity during pregnancy causes decreased PI3-K p85 $\alpha$ and GLUT-4 mRNA expression and higher IRS-2 and decreased PI3-K p85 $\alpha$ protein expression in placental tissue (Colomiere et al. 2009).

To date, there is a paucity of data available examining the effect of diabetes in pregnancy with and without obesity on the insulin-signalling pathway in human skeletal muscle and adipose tissue. Moreover, studies are yet to establish the effects of obesity in pregnancy independently. Thus, the purpose of this study was to determine whether transduction of insulin-signalling pathway and glucose transport is hindered in maternal tissues from women with GDM (in the presence or absence of obesity). Furthermore, as studies have suggested obesity may have a negative impact on insulin sensitivity and secretion, we investigated insulin-signalling components in NGT obese patients to determine the sole affects of obesity on insulin signalling and glucose transport. Increased knowledge of the possible defects present in the insulin-signalling pathway may aid us to better understand the pathophysiology of GDM and maternal obesity in pregnancy.

\section{Materials and methods}

\section{Patients and sample collection}

Subcutaneous adipose tissue (anterior abdominal wall) and pyramidalis skeletal muscle (anterior to the rectus abdominis) (between 300 and $500 \mathrm{mg}$ ) were obtained from a total of 64 pregnant women (with institutional research and ethics committee approval) undergoing elective caesarean section (term $>37$ weeks gestation, indications for caesarean section were breech presentation and/or previous caesarean section). Women with any underlying medical conditions such as asthma, polycystic ovarian syndrome, pre-eclampsia and macrovascular complications were excluded. The tissues were collected and prepared as previously described (Lappas et al. 2004, 2005, 2007a). Briefly, dissections of adipose tissue and skeletal muscle were obtained within $10 \mathrm{~min}$ of delivery. Tissues were bluntly dissected to remove visible connective tissue, blotted dry on filter paper, and either snap frozen in liquid nitrogen and stored at $-80{ }^{\circ} \mathrm{C}$ until further analysis, or paraffin embedded for hematoxylin and eosin (H\&E) analysis. H\&E was performed on tissue collected to ensure that all connective tissue was removed from the adipose tissue and skeletal muscle, and that skeletal muscle was free of adipose tissue (data not shown). Women were screened for GDM and were diagnosed according to the criteria set by the Australasian Diabetes in Pregnancy Society (ADIPS) at 24-28 weeks gestation, by either a fasting venous plasma glucose level of 5.5 and/or $8.0 \mathrm{mmol} / 1$ glucose or higher $2 \mathrm{~h}$ after a $75 \mathrm{~g}$ oral glucose load. Body mass index (BMI; weight $(\mathrm{kg}) /$ height $^{2}\left(\mathrm{~m}^{2}\right)$ was calculated based on measurements from patients' first antenatal visit ( $\sim 12$ weeks gestation). Non-obese pregnant women had a BMI of $\sim 25 \mathrm{~kg} / \mathrm{m}^{2}$ and obese patients had a BMI of $>30 \mathrm{~kg} / \mathrm{m}^{2}$.

\section{Whole cell lysate preparation}

Whole-protein lysate was prepared as previously described with minor amendments (Lappas et al. 2007b, Reti et al. 2007a). Adipose tissue and skeletal muscle lysates were prepared by homogenising $\sim 100 \mathrm{mg}$ tissue $(2 \times 20 \mathrm{~s}$ bursts $)$ in 300 and $500 \mu \mathrm{l}$ respectively of radioimmunoprecipitation assay buffer (50 mM Tris- $\mathrm{HCl}, \mathrm{pH} 7 \cdot 4,150 \mathrm{mM} \mathrm{NaCl}, 1 \%$ Igepal, $0 \cdot 1 \%$ SDS, $0 \cdot 25 \%$ Na deoxycholate, $1 \mathrm{mM}$ EDTA, pH $7 \cdot 4,1 \mathrm{mM}$ AEBSF, $10 \mu \mathrm{g} / \mathrm{ml}$ aprotinin, $5 \mu \mathrm{g} / \mathrm{ml}$ leupeptin, $1 \mathrm{mM}$ activated $\mathrm{Na}_{3} \mathrm{VO}_{4}$ and $1 \mathrm{mM} \mathrm{NaF}$ ) with a metal blade tissue homogeniser (Ultraturrax, S25N 8G dispersing tool; Jenke and Kunkel GmbH and Co., Staufen, Germany). Tissue homogenates were incubated at $4{ }^{\circ} \mathrm{C}$ for $1 \mathrm{~h}$ on a rotator. Homogenates were centrifuged at $15000 \mathrm{~g}$ for $20 \mathrm{~min}$. The supernatant was collected and respun. Whole-protein 
lysates were assayed for protein concentration using BCA protein assay (Pierce Chemical Co., Rockford, IL, USA) with BSA as the reference standard (Lappas et al. 2003).

\section{Plasma membrane protein extraction}

Briefly, $100 \mathrm{mg}$ adipose tissue and skeletal muscle were homogenised in 300 and $500 \mu \mathrm{l}$ respectively of HEPESsucrose buffer (25 mM HEPES, $250 \mathrm{mM}$ sucrose, $1 \mathrm{mM}$ AEBSF, $10 \mu \mathrm{g} / \mathrm{ml}$ aprotinin, $5 \mu \mathrm{g} / \mathrm{ml}$ leupeptin, $1 \mathrm{mM}$ activated $\mathrm{Na}_{3} \mathrm{VO}_{4}$ and $1 \mathrm{mM} \mathrm{NaF}$ ). Tissue homogenates were incubated at $4{ }^{\circ} \mathrm{C}$ for $1 \mathrm{~h}$ in a rotator. Homogenates were then centrifuged for $10 \mathrm{~min}$ at $1000 \mathrm{~g}$. The supernatant was collected and was centrifuged for $20 \mathrm{~min}$ at $10000 \mathrm{~g}$. The supernatant was collected and centrifuged for $30 \mathrm{~min}$ at $25000 \mathrm{~g}$. The supernatant was collected and stored at $-80^{\circ} \mathrm{C}$ until further analysis. Protein concentrations were determined using Coomassie Protein Assay according to the manufacturer's instructions (Pierce Chemical Co). Coomassie Protein assay was used rather than BCA protein assay due to buffer incompatibility.

\section{SDS-PAGE and western blot}

SDS-PAGE and western blot were performed as described previously (Lappas et al. 2006, Reti et al. $2007 b)$. Briefly, $30 \mu \mathrm{g}$ adipose tissue and $50 \mu \mathrm{g}$ skeletal muscle whole-cell lysate were separated on $7.5 \%$ gels and resolved proteins were transferred to polyvinylidene fluoride (PVDF) membrane. All antibodies were purchased from Santa Cruz (Santa Cruz, CA, USA). For detection of GLUT transporters, $50 \mu \mathrm{g}$ adipose tissue and $80 \mu \mathrm{g}$ skeletal muscle HEPES-sucrose samples were separated on $15 \%$ gels and resolved proteins were transferred to PVDF membranes. Molecular weights were identified by comparison with the motility of a protein standard. Whole-cell lysate blots were incubated with rabbit polyclonal anti-IR- $\beta-C-19(0 \cdot 4 \mu \mathrm{g} / \mathrm{ml})$, rabbit polyclonal anti-IRS-1 (A-19) $(0 \cdot 8 \mu \mathrm{g} / \mathrm{ml})$ and rabbit polyclonal anti-IRS-2 (H-205) $(0 \cdot 8 \mu \mathrm{g} / \mathrm{ml})$, diluted in blocking buffer (5\% skimmed milk/TBS-T $(0.05 \%))$ for $48 \mathrm{~h}$ at $4{ }^{\circ} \mathrm{C}$. HEPES-sucrose blots were incubated with rabbit polyclonal anti-GLUT-1 (H-43) $(0 \cdot 4 \mu \mathrm{g} / \mathrm{ml})$ and rabbit polyclonal anti-GLUT-4 $(0 \cdot 2 \mu \mathrm{g} / \mathrm{ml})$ diluted in blocking buffer II $(5 \%$ BSA/ TBS-T $(0.05 \%))$ for $24 \mathrm{~h}$ at $4{ }^{\circ} \mathrm{C}$.

Blots were probed with goat anti-rabbit IgG HRP $(0.02 \mu \mathrm{g} / \mathrm{ml})$-conjugated antibody in the corresponding blocking buffer for $1 \mathrm{~h}$ at room temperature. Proteins were detected using chemiluminescence kit according to the manufacturer's instructions (Luminol, Santa Cruz) and membranes were developed using the Chemidoc XRS (Bio-Rad).
All blots were stripped $(62.5 \mathrm{mM}$ Tris, $\mathrm{pH} 7 \cdot 4,2 \%$ SDS and $0 \cdot 1 \mathrm{M} \beta$-mercaptoethanol) and reprobed with goat polyclonal actin $(\mathrm{C}-11 ; 0.4 \mu \mathrm{g} / \mathrm{ml})$ in blocking buffer in order to ensure even loading and normalisation of blots.

Densitometry was performed on all blots to determine the density of the bands $\left(\mathrm{OD} / \mathrm{mm}^{2}\right)$ using Quantity One 4.6.6 image analysis program (Bio-Rad Laboratories). Separate western blots were run for each comparison (i.e. NGT (non-obese) versus GDM (non-obese); NGT (obese) versus GDM (obese)) and NGT subjects (NGT (non-obese) versus NGT (obese)). Expression of proteins was calculated as a ratio.

\section{In-house PI3-K p85 $\alpha$ and p110 ELISA}

Total protein levels of PI3-K p85 $\alpha$ and PI3-K p110 were quantified via in-house sandwich ELISA using antibodies purchased from Santa Cruz. Linearity of ELISA was determined with the use of placental lysate with an $r^{2} \geq 0 \cdot 98$. Briefly, microwell titre plates (Nunc, Maxisorp, Roskilde, Denmark) were incubated over $48 \mathrm{~h}$ at $4{ }^{\circ} \mathrm{C}$ with goat polyclonal anti-PI3K p85 $\alpha(\mathrm{N}-18)$ $(2 \mu \mathrm{g} / \mathrm{ml})$ and goat polyclonal anti-PI3K p110 $\alpha$ (I-19) $(2 \mu \mathrm{g} / \mathrm{ml})$ in PBS. Plates were washed with wash buffer (PBS with $0.05 \%$ Tween, PBS-T) and blocked with blocking buffer (1\% BSA/PBS-T). Plates were washed again and $30 \mu \mathrm{g}$ adipose tissue or $50 \mu \mathrm{g}$ skeletal muscle diluted in blocking buffer were added to the plates and incubated at room temperature for $1 \mathrm{~h}$. Rabbit polyclonal anti-PI3K p85 $\alpha$ (Z-8) $(2 \mu \mathrm{g} / \mathrm{ml})$ and mouse monoclonal anti-PI3K p110 $\alpha$ (D-4) $(2 \mu \mathrm{g} / \mathrm{ml})$ diluted in blocking buffer were added to wells and incubated for $2 \mathrm{~h}$ at room temperature. Plates were washed with wash buffer followed by incubation with goat anti-rabbit IgG HRP-conjugated antibody $(0 \cdot 04 \mu \mathrm{g} / \mathrm{ml})$ and goat anti-mouse IgG HRP antibody $(0.04 \mu \mathrm{g} / \mathrm{ml}))$ for $1 \mathrm{~h}$ at room temperature. Final washes were performed and TMB (Sigma-Aldrich) was added to wells for colorimetric detection. Sulphuric acid $(1 \cdot 8 \mathrm{M})$ was added to stop the reaction and plates were read at $450 \mathrm{~nm}$ using a Bio-Rad microplate reader (Bio-Rad Laboratories). Blanks (no sample), positive (placental lysate) and negative controls (placental lysate plus blocking peptide) were run on every plate to verify binding specificity. For negative controls, five times the volume of blocking peptide (sc-31969P and sc-7248P, Santa Cruz) for each antibody used for coating the plate was combined with $2 \mu \mathrm{g} / \mathrm{ml}$ antibody and incubated on a rotator overnight at $4{ }^{\circ} \mathrm{C}$. The blocking peptide mixture was then added to the plate rather than coating antibody for the negative control samples. Total protein levels of PI3-K p85 $\alpha$ and PI3-K p110 were semi-quantitatively calculated according to absorbance readings. 


\section{RNA extraction and real-time PCR}

Total RNA was extracted from $\sim 100 \mathrm{mg}$ skeletal muscle and adipose tissue. Extraction was performed using TRI Reagent according to the manufacturer's instructions (Sigma-Aldrich). RNA concentrations were quantified using a spectrophotometer (Smart Spec, Bio-Rad). RNA quality and integrity were determined via the $A_{260}: A_{280}$ ratio and agarose gel electrophoresis. One microgram of RNA was converted to cDNA using the iScript cDNA Synthesis Kit according to the manufacturer's instructions (Bio-Rad). One microlitre of cDNA was used to perform reverse transcription (RT)-PCR using Sensimix Plus SYBR green (Alexandria, New South Wales, Australia) and primers as listed below. $\beta$-actin was chosen as a suitable reference gene to normalise the mRNA expression and additionally to keep consistent with western blot data. The specificity of the product was assessed from melting curve analysis. All plates were run with a positive (placental cDNA) and negative (RNA without reverse transcriptase) control to ensure quality of run and confirm the absence of contamination. Pre-validated primers for IR (QT00082810), IRS-1 (QT00074144), IRS-2 (QT00064036), PI3-K p85 $\alpha$ (QT,01005984) PI3K p110 $\alpha$ (QT00014861), PI3K p110ß QT00029148), GLUT-1 (QT00068957), GLUT-4 (QT00097902), GSK-3 $\alpha$ (QT00075306), GSK$3 \beta$ (QT00057134), IGFBP1 (QT00049427), PEPCK (QT00001197), PDK-1 (QT00063077) and $\beta$-actin (QT00095431) were purchased from Qiagen. The cycling conditions for RT-PCR were as follows: $95^{\circ} \mathrm{C}$ for $3 \mathrm{~min} ; 95^{\circ} \mathrm{C}$ for $15 \mathrm{~s}$ (denaturation); $55^{\circ} \mathrm{C}$ for $45 \mathrm{~s}$ (annealing); $72{ }^{\circ} \mathrm{C}$ for $45 \mathrm{~s}$ (extension); cycle 39 times; $95{ }^{\circ} \mathrm{C}$ for $1 \mathrm{~min} ; 55^{\circ} \mathrm{C}$ for $1 \mathrm{~min}$; a melt curve analysis was programmed for 55 to $95^{\circ} \mathrm{C}\left(1{ }^{\circ} \mathrm{C}\right.$ intervals $)$ and held for $20 \mathrm{~s}$. Real-time PCR results were calculated according to the $2^{-\Delta \Delta C_{\mathrm{t}}}$ method previously described (Livak \& Schmittgen 2001). NGT (non-obese) or NGT (obese) subgroups were used as calibrators.

\section{Statistical analysis}

Statistical analyses were performed using a commercially available statistical software package (Statgraphics, STSC, Rockville, MD, USA). Unless otherwise stated, sample comparison was analysed by Student's $t$-test. When data were not normally distributed, Mann-Whitney $U$ tests were used. Statistical difference was indicated by $P$ value $<0 \cdot 05$. Data are expressed as the mean \pm s.E.M.

\section{Results}

The mRNA and protein expression of insulinsignalling components in adipose tissue and skeletal muscle from i) non-obese GDM compared to nonobese NGT patients, ii) obese GDM compared to obese NGT patients and iii) NGT non-obese compared to NGT obese patients $(n=7-8$ per subgroup unless otherwise specified) were compared in this study.

\section{Participants}

Demographic data of all participants involved in this study are summarised in Table 1 . Maternal age did not differ among groups. Maternal BMI at 12 weeks was significantly higher in non-obese and obese GDM women compared to NGT controls. Fasting, 1 and $2 \mathrm{~h}$ OGTT readings were all significantly higher in both non-obese and obese GDM women in comparison to BMI-matched NGT pregnant controls. Gestational age of obese GDM women was significantly lower compared to obese NGT pregnant women. Obese NGT women had higher 12-week and term BMI, and fasting and $1 \mathrm{~h}$ OGTT readings when compared to non-obese NGT controls. Out of 59 participants, 12 had a family history of T2DM (mother, father or grandparents).

Table 1 Patient characteristics for study group

\begin{tabular}{|c|c|c|c|c|}
\hline & \multicolumn{2}{|c|}{ Non-obese } & \multicolumn{2}{|c|}{ Obese } \\
\hline & NGT $(n=16)$ & GDM-insulin $(n=13)$ & NGT $(n=15)$ & GDM-insulin $(n=15)$ \\
\hline 12-week BMI $\left(\mathrm{kg} / \mathrm{m}^{2}\right)$ & $22 \cdot 1 \pm 0 \cdot 4$ & $24.5 \pm 0.6^{*}$ & $34.8 \pm 0.9^{\dagger}$ & $38 \cdot 5 \pm 1 \cdot 4^{*}$ \\
\hline Term BMI $\left(\mathrm{kg} / \mathrm{m}^{2}\right)$ & $27 \cdot 0 \pm 0.5$ & $29 \cdot 1 \pm 1 \cdot 0$ & $39 \cdot 3 \pm 1 \cdot 2^{\dagger}$ & $41 \cdot 1 \pm 1 \cdot 4$ \\
\hline O h OGTT $(\mathrm{mmol} / \mathrm{l})$ & $4 \cdot 2 \pm 0 \cdot 1$ & $4.9 \pm 0.5^{\star}$ & $4 \cdot 7 \pm 0 \cdot 1^{\dagger}$ & $5 \cdot 7 \pm 0 \cdot 3^{\star}$ \\
\hline $1 \mathrm{~h}$ OGTT $(\mathrm{mmol} / \mathrm{l})$ & $6 \cdot 2 \pm 0.3$ & $10 \cdot 4 \pm 1 \cdot 0^{*}$ & $7 \cdot 7 \pm 0.4^{\dagger}$ & $11 \cdot 1 \pm 0.5^{\star}$ \\
\hline 2 h OGTT $(\mathrm{mmol} / \mathrm{l})$ & $5.5 \pm 0.3$ & $8.6 \pm 0.8^{*}$ & $6.0 \pm 0.2$ & $9 \cdot 0 \pm 0.5^{\star}$ \\
\hline Maternal age (years) & $33 \cdot 6 \pm 1 \cdot 2$ & $33.4 \pm 0.6$ & $33 \cdot 7 \pm 1 \cdot 0$ & $34 \cdot 6 \pm 1 \cdot 6$ \\
\hline Birth weight $(\mathrm{g})$ & $3359 \pm 110$ & $3205 \pm 115$ & $3619 \pm 96$ & $3546 \pm 120$ \\
\hline Gestation (weeks) & $38.8 \pm 0.2$ & $38.4 \pm 0.2$ & $38.8 \pm 0.2$ & $38 \cdot 1 \pm 0.2^{*}$ \\
\hline Gravida & $3.0 \pm 0.4$ & $2 \cdot 8 \pm 0.3$ & $2 \cdot 4 \pm 0.3$ & $3.2 \pm 0.4$ \\
\hline Parity & $2 \cdot 2 \pm 0.2$ & $2 \cdot 2 \pm 0.2$ & $1 \cdot 9 \pm 0.2$ & $2 \cdot 3 \pm 0 \cdot 3$ \\
\hline
\end{tabular}

Values represent mean \pm S.E.M. BMI, body mass index; NGT, normal glucose tolerant; OGTT, oral glucose tolerance test. Student's $t$-test ${ }^{*} P<0.05$ NGT versus GDM-insulin. ${ }^{\dagger} P<0.05$ NGT (non-obese) versus NGT (obese). 

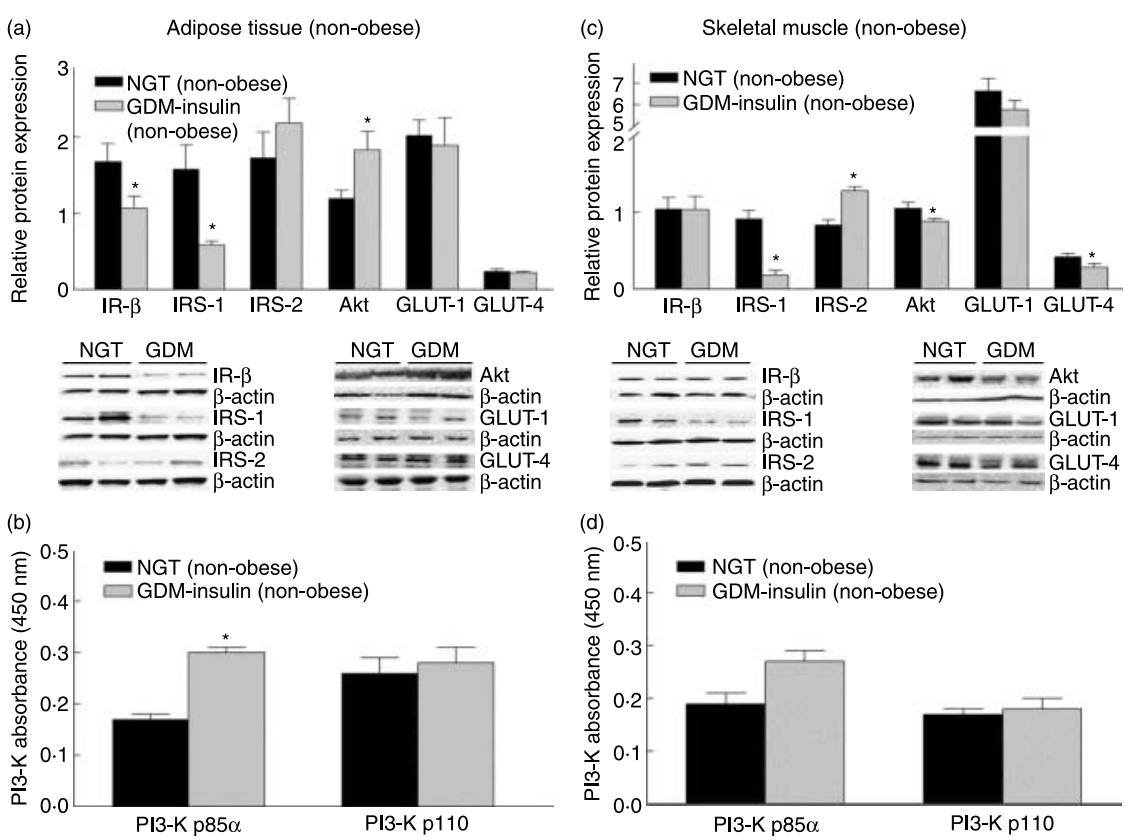

Figure 1 Protein expression of IR- $\beta$ (95 kDa), IRS-1 (180 kDa), IRS-2 (170 kDa), Akt (60 kDa), GLUT-1 (55 kDa) and GLUT-4 (43 kDa) in adipose tissue (a) and skeletal muscle (c) collected from a non-obese pregnant cohort ( $n=7-8$ per group). Each bar represents the relative expression of the protein of interest \pm S.E.M. A representative western blot image of two patients from each group has been included. All blots were stripped and reprobed with $\beta$-actin (adipose tissue) or actin (skeletal muscle) to normalise for protein load. Protein expression of PI3-K p85 $\alpha$ and PI3-K p110 in adipose tissue (b) and skeletal muscle (d) collected from the non-obese pregnant cohort ( $n=8$ per group). Expression is measured via absorbance reading at $450 \mathrm{~nm}$. Student's $t$-test, ${ }^{*} P<0.05$ NGT versus GDM.

\section{Expression studies}

The effects of GDM in pregnancy on insulin signalling and glucose transport in adipose tissue and skeletal muscle in a non-obese cohort

Quantitative RT-PCR performed on subcutaneous adipose tissue biopsies showed altered gene expression in GDM women when compared to NGT non-obese subjects. Specifically, decreased IRS-1 and GLUT-4 and increased IRS-2, GLUT-1, GSK-3 $\alpha$, GSK-3 $\beta$, IGFBP1 and PDK-1 mRNA expression were seen in GDM women compared to NGT subjects. No differences were found in mRNA expression of IR, PI3-K p85 $\alpha$, PI3-K p110 $\alpha$, PI3-K p110 $\beta$ and PEPCK. Protein expression of IR- $\beta$ and IRS-1 was also lower, while PI3-K p $85 \alpha$ and Akt protein expression were higher in GDM women compared to NGT controls. Protein expression of IRS-2, GLUT-1 and -4 transporters was unaltered between the two groups.

For skeletal muscle, there was lower IRS-1, PI3-K p85 $\alpha$, GLUT-1, GLUT-4, GSK-3 $\alpha$, GSK3- $\beta$ and PDK-1 mRNA expression in GDM women compared to NGT controls. The mRNA expression of IR, IRS-2, PI3-K p110 $\alpha$, PI3-K p110 $\beta$, IGFBP1 and PEPCK remained unchanged between the two groups. At a protein level, skeletal muscle IRS-1, Akt and GLUT-4 were lower, and IRS-2 and PI3-K p85 $\alpha$ were higher in GDM women compared to NGT controls. IR- $\beta$ and GLUT-1 protein expression remained unchanged in between the two groups.

The effects of GDM in pregnancy on insulin signalling and glucose transport in adipose tissue and skeletal muscle in an obese cohort

In adipose tissue biopsies, RT-PCR analysis showed lower IRS-1 and GLUT-4 mRNA expression in GDM women when compared to NGT controls (Fig. 1). No changes were noted in IR, IRS-2, PI3-K p85 $\alpha$, PI3-K p110 $\alpha$, PI3-K p110 $\beta$, GLUT-1, GSK-3 $\alpha$, GSK-3 $\beta$, IGFBP1, PEPCK and PDK-1 mRNA expression between the two cohorts. Adipose tissue protein expression of IR- $\beta$ and IRS-1 was lower in GDM women, while IRS-2, Akt and PI3-K p $85 \alpha$ expression were increased respective to NGT controls. An unexpected increase in GLUT-4 protein expression was noted in GDM women, while GLUT-1 protein expression was significantly decreased when compared to NGT controls.

Skeletal muscle mRNA expression of GLUT-4 and GSK-3 $\alpha$ was significantly lower in GDM women compared to NGT obese controls. No changes in mRNA expression of IR, IRS-1, IRS-2, PI3-K p85 $\alpha$, 

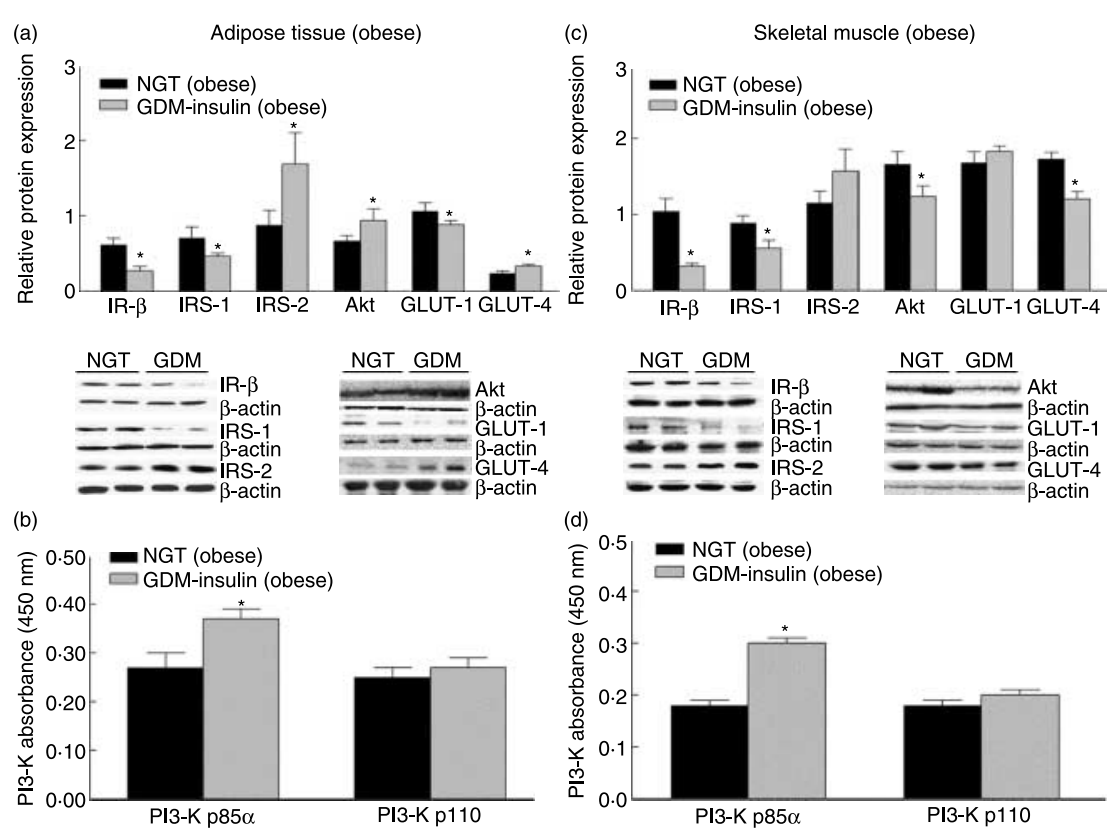

Figure 2 Protein expression of IR- $\beta$ (95 kDa), IRS-1 (180 kDa), IRS-2 (170 kDa), Akt $(60 \mathrm{kDa})$, GLUT-1 (55 kDa) and GLUT-4 (43 kDa) in adipose tissue (a) and skeletal muscle (c) collected from an obese pregnant cohort ( $n=7-8$ per group). Each bar represents the relative expression of the protein of interest \pm S.E.M. A representative western blot image of two patients from each group has been included. All blots were stripped and reprobed with $\beta$-actin (adipose tissue) or actin (skeletal muscle) to normalise for protein load. Protein expression of PI3-K p85 $\alpha$ and PI3-K p110 in adipose tissue (b) and skeletal muscle (d) collected from the obese pregnant cohort ( $n=8$ per group). Expression is measured via absorbance reading at $450 \mathrm{~nm}$. Student's $t$-test, ${ }^{\star} P<0.05$ NGT versus GDM.

PI3-K p110 $\alpha$, PI3-K p110 $\beta$, GLUT-1, GSK-3 $\beta$, IGFBP1, PEPCK and PDK-1 were noted between the two groups. Furthermore, in GDM women, skeletal muscle protein expression of IR- $\beta$, IRS-1, Akt and GLUT- 4 was reduced, while PI3-K p85 $\alpha$ was increased compared to NGT controls. Skeletal muscle GLUT-1 transporter protein expression remained unchanged between the two groups.

The effects of obesity in pregnancy on insulin signalling and glucose transport in adipose tissue and skeletal muscle in a NGT cohort

Adipose tissue biopsies obtained from obese subjects displayed higher IRS-2 mRNA expression and lower GLUT-1 and -4 mRNA expression when compared to non-obese controls (Fig. 2). IR, IRS-1, PI3-K p85 $\alpha$, PI3-K p110 $\alpha$, PI3-K p110 $\beta$, GSK-3 $\alpha$, GSK-3 $\beta$, IGFBP1, PEPCK and PDK-1 gene expression remained unchanged between the two cohorts. Higher protein expression of PI3-K p85 $\alpha$ and lower GLUT-1 expression in the obese cohort were found compared to non-obese controls (Table 2). Adipose tissue protein expression of IR- $\beta$, IRS-1 and IRS-2 was unaltered between nonobese and obese cohorts (Fig. 3).
Skeletal muscle mRNA expression of GLUT-1 and -4 and GSK-3 $\beta$ was lower, while PEPCK mRNA expression was higher in obese women compared to non-obese controls. However, there were no differences in skeletal muscle mRNA expression of IR, IRS-1, PI3-K p $85 \alpha$, PI3-K p110 $\alpha$, PI3-K p110 $\beta$, GSK-3 $\alpha$, IGFBP1 and PDK-1 between the two groups. Lower skeletal muscle IRS-1 and GLUT-4 expression and higher IRS-2 protein expression were found in obese subjects when compared to non-obese controls. No changes were found in IR- $\beta$, PI3-K p85 $\alpha$, PI3-K p110 and GLUT-1 protein expression between the two groups.

\section{Discussion}

The data presented in this study provide evidence that diabetes and obesity during pregnancy cause defects in the insulin-signalling pathway in both adipose tissue and skeletal muscle. The action of insulin through the transduction of the insulin-signalling pathway mediates a wide variety of cellular responses including glucose transport via GLUTs, glycogen synthesis, protein synthesis and lipid metabolism. Thus, defects in the 
Table 2 mRNA expression of insulin-signalling intermediates

NGT

(non-obese) $(n=8)$
GDM-insulin

(non-obese) $(n=8)$

\section{NGT}

(obese) $(n=8)$

In adipose tissue

$\begin{array}{ll}\text { IR- } \beta & 4.26 \pm 1.65 \\ \text { IRS-1 } & 7 \cdot 18 \pm 0.93 \\ \text { IRS-2 } & 2 \cdot 21 \pm 0.24 \\ \text { PI3-K p85 } \alpha & 1.56 \pm 0.15 \\ \text { PI3-K p110 } \alpha & 1.20 \pm 0.17 \\ \text { PI3-K p110 } \beta & 2 \cdot 12 \pm 0.43 \\ \text { GLUT-1 } & 0.50 \pm 0.05 \\ \text { GLUT-4 } & 0.91 \pm 0.10 \\ \text { GSK-3 } \alpha & 0.19 \pm 0.03 \\ \text { GSK-3 } \beta & 0.75 \pm 0.20 \\ \text { IGFBP1 } & 3.86 \times 10^{-4} \pm 1.59 \times 10^{-4} \\ \text { PEPCK } & 1.30 \pm 0.72 \\ \text { PDK-1 } & 0.30 \pm 0.09\end{array}$

In skeletal muscle

IRS-1 71.05 17.73

IRS-2 2.63 20.26

PI3-K p85 $\alpha \quad 8.35 \pm 1.39$

PI3-K p110 $\alpha \quad 12.78 \pm 2.94$

PI3-K p110 $\quad 6 \cdot 19 \pm 0.71$

GLUT-1 $\quad 0 \cdot 79 \pm 0.15$

GLUT-4 16.45 $12 \cdot 25$

GSK-3 $\alpha$

GSK-3 $\beta$

IGFBP1

PEPCK

PDK-1
$2.71 \pm 0.64$

$4.99 \pm 0.94$

$1.54 \times 10^{-3} \pm 6.22 \times 10^{-4}$

$1.95 \times 10^{-2} \pm 1.38 \times 10^{-2}$

$4.95 \pm 0.98$

$2 \cdot 07 \pm 0.62$
$4 \cdot 44 \pm 0.63^{\star}$
$3.54 \pm 0.61^{\star}$
$2 \cdot 80 \pm 0.86$
$1.98 \pm 0.51$
$3 \cdot 12 \pm 0.72$
$0.65 \pm 0.06^{\star}$
$0.36 \pm 0.08^{\star}$
$0.41 \pm 0.08^{\star}$
$1.36 \pm 0.21^{\star}$
$0.01 \pm 5.86 \times 10^{-3 *}$
$2.70 \pm 1.15$
$0.78 \pm 0.16^{\star}$

$0 \cdot 78 \pm 0.16^{*}$

$24 \cdot 43 \pm 3 \cdot 95$
$39 \cdot 89 \pm 5 \cdot 22^{\star}$
$3 \cdot 34 \pm 0 \cdot 40$
$5 \cdot 16 \pm 1 \cdot 30^{\star}$
$11 \cdot 74 \pm 1 \cdot 30$
$9 \cdot 21 \pm 3 \cdot 28$
$0 \cdot 39 \pm 0 \cdot 06^{\star}$
$9 \cdot 61 \pm 1 \cdot 48^{\star}$
$0 \cdot 99 \pm 0 \cdot 33^{\star}$
$1 \cdot 96 \pm 0 \cdot 46^{\star}$
$4 \cdot 04 \times 10^{-3} \pm 1 \cdot 38 \times 10^{-3}$
$2 \cdot 61 \times 10^{-2} \pm 7.84 \times 10^{-3}$
$2 \cdot 44 \pm 0.82^{\star}$

$1 \cdot 91 \pm 0 \cdot 78$
$8 \cdot 20 \pm 1 \cdot 24$
$3 \cdot 61 \pm 0 \cdot 61^{\dagger}$
$3 \cdot 75 \pm 1 \cdot 25$
$1 \cdot 58 \pm 0 \cdot 38$
$2 \cdot 31 \pm 0 \cdot 50$
$0 \cdot 36 \pm 0 \cdot 05^{\dagger}$
$0 \cdot 60 \pm 0 \cdot 07^{\dagger}$
$0 \cdot 17 \pm 0 \cdot 03$
$0 \cdot 94 \pm 0 \cdot 29$
$4 \cdot 36 \times 10^{-3} \pm 2 \cdot 21 \times 10^{-3}$
$1 \cdot 44 \pm 0 \cdot 79$
$0 \cdot 36 \pm 0 \cdot 17$

$29 \cdot 01 \pm 5 \cdot 40$
$52 \cdot 78 \pm 10 \cdot 22$
$3 \cdot 21 \pm 0 \cdot 60$
$6 \cdot 31 \pm 1 \cdot 06$
$12 \cdot 19 \pm 1 \cdot 90$
$9 \cdot 21 \pm 2 \cdot 37$
$0 \cdot 44 \pm 0 \cdot 09^{\dagger}$
$11 \cdot 46 \pm 1 \cdot 61^{\dagger}$
$3 \cdot 15 \pm 1 \cdot 27$
$2 \cdot 65 \pm 0 \cdot 51^{\dagger}$
$1 \cdot 20 \times 10^{-2} \pm 7 \cdot 86 \times 10^{-3}$
$0 \cdot 11 \pm 0 \cdot 04^{\dagger}$
$4 \cdot 72 \pm 1 \cdot 53$

GDM-insulin

(obese) $(n=8)$

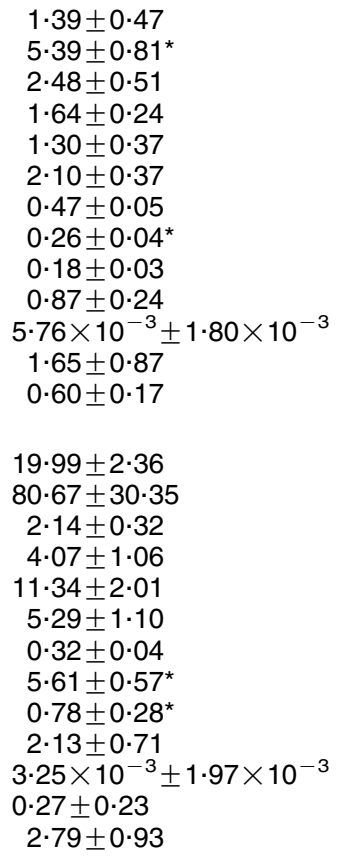

Values represent mean \pm S.E.M. NGT, normal glucose tolerant. Student's $t$-test ${ }^{*} P<0.05$ NGT versus GDM-insulin. ${ }^{\dagger} P<0.05$ NGT (non-obese) versus NGT (obese).

insulin-signalling pathway may negatively impact on downstream pathways involved in glucose transport, glycogen synthesis and lipid metabolism.

Our study has demonstrated that, compared to NGT women, altered adipose tissue insulin signalling is present at multiple sites in lean GDM women, obese GDM women and minimal changes in obese NGT women. In our non-obese cohort, we demonstrate decreased mRNA expression of IRS-1 and increased mRNA expression of IRS-2 and PDK-1 in adipose tissue from GDM women compared to NGT controls. Further to this, lower protein expression of IR- $\beta$ and IRS- 1 and higher Akt and PI3-K p85 $\alpha$ expression were found in adipose tissue from GDM women. Similar protein expression was noted in our obese GDM cohort with the addition of higher IRS-2 protein expression. IRS-1 mRNA expression was lower in adipose tissue from obese GDM women compared to BMI-matched controls. Furthermore, in our NGT cohort, obese pregnant women displayed higher IRS-2 mRNA expression compared to non-obese controls.

In skeletal muscle samples, lower IRS-1 and PI3-K $\mathrm{p} 85 \alpha$ expression were found in non-obese GDM women. In addition, higher IRS-2 and PI3-K p85 $\alpha$ expression and lower IRS-1 and Akt protein expression were noted in GDM women from the non-obese cohort. Similar results were seen in the obese GDM women with the addition of lower IR- $\beta$ protein expression. Skeletal muscle from NGT obese women had lower IRS-1 and higher IRS-2 expression. Overall, the results obtained suggest impaired insulin signalling in adipose tissue and skeletal muscle in women with GDM (both non-obese and obese) and to a lesser extent in women with maternal obesity. These results are in support of previous data obtained (Friedman et al. 1999, Catalano et al. 2002, Tomazic 2002). Collectively, these data suggest that both diabetes and obesity can impact on components of the insulin-signalling pathway. Defects in these proteins may alter downstream functions such as glucose uptake.

There is much evidence to suggest that adipose tissue plays a central role in the development of insulin resistance (Hajer et al. 2008) where adipose tissue itself is insulin responsive and contributes directly, although quantitatively less than skeletal muscle, to whole-body glucose disposal (Stump et al. 2006). Skeletal muscle plays an important role in glucose metabolism as it mediates $75 \%$ of all insulin-mediated glucose disposal under normal physiological conditions 

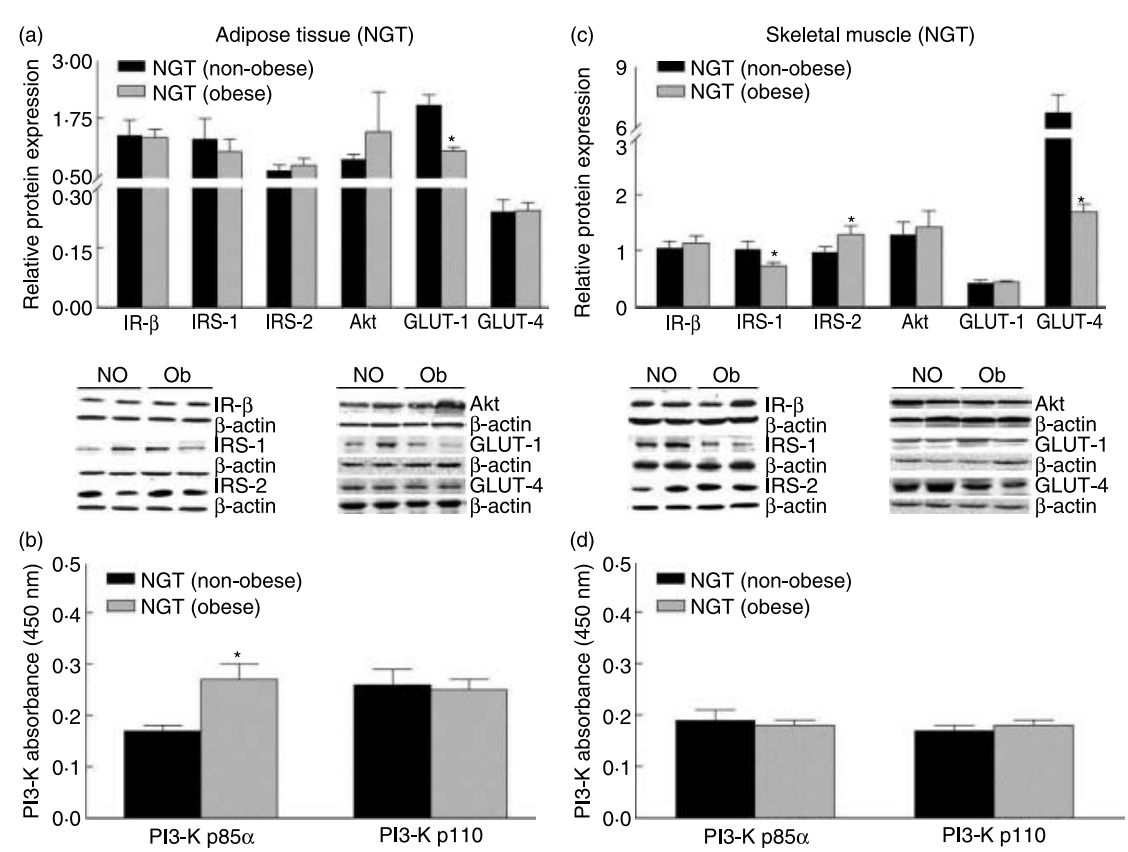

Figure 3 Protein expression of IR- $\beta$ (95 kDa), IRS-1 (180 kDa), IRS-2 (170 kDa), Akt (60 kDa), GLUT-1 (55 kDa) and GLUT-4 (43 kDa) in adipose tissue (a) and skeletal muscle (c) collected from NGT pregnant cohort ( $n=7-8$ per group). Each bar represents the relative expression of the protein of interest \pm s.E.M. A representative western blot image of two patients from each group has been included. All blots were stripped and reprobed with $\beta$-actin (adipose tissue) or actin (skeletal muscle) to normalise for protein load. Protein expression of PI3-K p85 $\alpha$ and PI3-K p110 in adipose tissue (b) and skeletal muscle (d) collected from the non-obese pregnant cohort ( $n=8$ per group). Expression is measured via absorbance reading at $450 \mathrm{~nm}$. Student's $t$-test, ${ }^{\star} P<0.05$ NGT (non-obese) versus NGT (obese).

(Stump et al. 2006). The action of insulin to increase glucose uptake is controlled initially by the transport of glucose across the cell membrane, which takes place by facilitated diffusion of GLUT-4 (Scheck et al. 1991). Studies in T2DM models have demonstrated impaired glucose transport via IRS-1/PI3-K-dependent signalling (Scheck et al. 1991, Rondinone et al. 1997).

In this study, GLUT-1 and -4 transporters were investigated. In response to GDM, GLUT-4 mRNA expression was lower in both skeletal muscle and adipose tissue in both non-obese and obese GDM cohorts and NGT obese women. Skeletal muscle protein expression was similar to mRNA expression, while adipose tissue demonstrated no changes in GLUT-4 transporter with the exception of higher GLUT-4 in adipose tissue from obese GDM women compared to controls. GLUT-1 mRNA expression was lower in both adipose tissue and skeletal muscle from non-obese GDM women and NGT obese women compared to non-obese NGT controls. No changes in skeletal muscle protein expression were noted, but adipose tissue demonstrated lower GLUT-1 expression in both obese GDM women and obese NGT women compared to controls.
Overall decreased GLUT expression in both tissues was noted in individuals with GDM and/or obesity. Others have shown that GLUT-4 and subsequent glucose uptake is lower in adipose tissue and skeletal muscle from women with GDM (Garvey et al. 1992, 1993). This may be caused by defective insulinsignalling upstream as discussed above. Consequently, blood glucose levels remain high in the maternal bloodstream as there is a decreased capacity, due to lower GLUT transporter expression, to uptake glucose into the cell. Our data demonstrate that women with obesity and/or GDM have decreased adipose tissue and skeletal muscle GLUT-4 transport consequently increasing free glucose within maternal blood circulation and availability to the placenta. In keeping with this, our previous studies have shown increased GLUT-1 expression in the GDM placenta (Colomiere et al. 2009). Furthermore, studies have shown increased maternal-foetal glucose transport in placenta from women with insulin-controlled GDM (Osmond et al. 2001). The combination of these factors suggests that defective glucose transport prior to birth may be involved in pre-programming the foetus for increased risk of diabetes and obesity in adulthood. 
PEPCK, a cytosolic decarboxylase enzyme involved in gluconeogenesis, is regulated by hormones that are involved in the maintenance of glucose homoeostasis (Holyoak et al. 2006). A secondary role for PEPCK is glyceroneogenesis, or the production of glycerol. This is essential for the synthesis of triglycerides and the release of free fatty acids (FFA) into the blood stream (Beale et al. 2004). Studies have shown glyceroneogenesis to occur in skeletal muscle (Nye et al. 2008). In addition, overexpression of cytosolic PEPCK in the skeletal muscle of the mouse resulted in a marked increase in intramyocellular triglyceride levels (Hakimi et al. 2007). In this study, skeletal muscle PEPCK mRNA expression was higher in obese NGT women compared to non-obese NGT controls. This increase could reflect the amount of triglycerides within these skeletal tissues, due to maternal obesity. Further investigation is warranted to elucidate the precise role of PEPCK overexpression and/or gluconeogenesis and reciprocal glyceroneogenesis in maternal obesity.

GSK- $3 \alpha$ and $-3 \beta$ are serine/threonine protein kinases that are involved in the storage of glucose into glycogen. Defects in GS activity and GSK-3 expression are early events in the development of insulin resistance where glycogen synthesis is impaired in T2DM (Eldar-Finkelman et al. 1999). Studies have shown that inhibition of GSK-3 in Zucker diabetic fatty rats leads to an improvement in both insulin action and glucose uptake (Cline et al. 2002). Our study demonstrates higher adipose tissue GSK-3 $(\alpha$ and $\beta$ ) mRNA expression in GDM women from both non-obese and obese cohorts compared to BMI-matched NGT controls. Previous studies performed in CHO/IR/IRS-1 cells overexpressing GSK-3 demonstrate decreased tyrosine phosphorylation of IRS-1 and IR- $\beta$ (Eldar-Finkelman \& Krebs 1997). Therefore, GSK-3 overexpression in adipose tissue may negatively impact on the insulin-signalling pathway, particularly at IR and its IRS-1, and thus may play a central role in the regulation of insulin action and glucose metabolism.

Previous studies have demonstrated overexpression of GSK-3 isoforms in skeletal muscle samples from insulin resistance states (Ciaraldi et al. 2006). In contrast to this, our study demonstrated lower skeletal muscle GSK-3 ( $\alpha$ and $\beta$ ) mRNA expression in GDM women. Additionally, skeletal muscle GSK-3 $\beta$ mRNA expression was decreased in obese NGT women. Others have demonstrated that insulin resistance in muscle cells reduces glucose uptake and local storage of glucose as glycogen (Patel et al. 2008).

The role for GSK-3 in skeletal muscle from diabetic pregnancies is currently unknown and the mechanisms behind GSK-3 require further investigations. Measuring glycogen synthase activity may aid to determine whether decreases in GSK-3 mRNA expression disrupt glycogen synthesis and furthermore establish the role of tissue-specific alterations in GSK-3 in women with GDM.

The development of insulin resistance during late pregnancy shifts maternal energy metabolism from carbohydrate to lipid oxidation and thus, spares glucose for the growing foetus (Sivan et al. 1998). In the third trimester, postprandial FFA levels increase and insulin sensitivity worsens by $40-60 \%$ compared with pre-pregnancy (Catalano et al. 1993, 1999). Insulin's ability to suppress whole-body lipolysis is reduced during late pregnancy (Sivan et al. 1999) and to a greater degree in women with GDM (Xiang et al. 1999), consequently contributing to increased postprandial FFA levels. An intracellular mechanism responsible for insulin suppression of lipolysis involves activation of the insulin-signalling pathway. Defects in the transduction of the insulin-signalling pathway can therefore increase adipocytes lipolysis and the release of FFA into the mother's bloodstream, where it may have an effect on skeletal muscle glucose metabolism and placental transport of nutrients between mother and foetus.

In conclusion, adipose tissue and skeletal muscle collected from women with maternal obesity or GDM (independent of obesity) display impaired insulin signalling, which appears to be regulated through IRS-1/Akt/PDK-1-dependent pathway. This study suggests that impaired insulin-signalling transduction disrupts glucose transport, glycogen synthesis and possibly disrupts lipid metabolism in adipose tissue. Furthermore, GSK-3 and enzymes involved in gluconeogenesis may be involved in both obesity and diabetes during pregnancy. Post-partum longitudinal studies, involving repeating this study on maternal tissues 1 year post-pregnancy, could confirm long-term effects of GDM and obesity during pregnancy. This would allow a more in-depth understanding into the aetiology of GDM and maternal obesity and the future risk of T2DM.

\section{Declaration of interest}

The authors declare that there is no conflict of interest that could be perceived as prejudicing the impartiality of the research reported.

\section{Funding}

This work was funded by the National Health and Medical Research Council (NHMRC) (grant no. 454310), Diabetes Australia Research Trust and Medical Research Foundation for Women and Babies. Dr Martha Lappas is in recipient of a NHMRC RD Wright Fellowship (grant no. 454777). Michelle Colomiere is in recipient of a Felix Meyer Postgraduate Scholarship at the University of Melbourne, Australia. 


\section{Author contribution statement}

M Colomiere carried out all experimental studies, did all the data/statistical analysis and wrote the manuscript; M Lappas conceived the study. M Permezel assisted in patient analysis. M Lappas drafted the manuscript and assisted in data analysis.

\section{Acknowledgements}

The authors gratefully acknowledge the contribution made by the clinical research midwives Anne Beeston, Valerie Bryant and Gabrielle De Bruyn, and the Obstetric and Midwifery staff at the Mercy Hospital for Women. The authors would also like to thank Sarah Holdsworth-Carson from the Department of Obstetrics and Gynaecology, University of Melbourne for assisting in sample collection and real-time PCR calculations.

\section{References}

Bayascas JR, Wullschleger S, Sakamoto K, Garcia-Martinez JM, Clacher C, Komander D, van Aalten DMF, Boini KM, Lang F, Lipina C et al. 2008 Mutation of the PDK1 PH domain inhibits protein kinase $\mathrm{B} / \mathrm{Akt}$, leading to small size and insulin resistance. Molecular and Cellular Biology 28 3258-3272.

Beale EG, Hammer RE, Antoine B \& Forest C 2004 Disregulated glyceroneogenesis: PCK1 as a candidate diabetes and obesity gene. Trends in Endocrinology and Metabolism 15 129-135.

Beischer NA, Wein P, Sheedy MT \& Steffen B 1996 Identification and treatment of women with hyperglycaemia diagnosed during pregnancy can significantly reduce perinatal mortality rates. Australian and New Zealand Journal of Obstetrics and Gynaecology 36 239-247.

Buchanan TA \& Xiang AH 2005 Gestational diabetes mellitus. Journal of Clinical Investigation 115 485-491.

Catalano PM, Tyzbir ED, Wolfe RR, Calles J, Roman NM, Amini SB \& Sims EA 1993 Carbohydrate metabolism during pregnancy in control subjects and women with gestational diabetes. American Journal of Physiology 264 E60-E67.

Catalano PM, Huston L, Amini SB \& Kalhan SC 1999 Longitudinal changes in glucose metabolism during pregnancy in obese women with normal glucose tolerance and gestational diabetes mellitus. American Journal of Obstetrics and Gynecology 180 903-916.

Catalano PM, Nizielski SE, Shao J, Preston L, Qiao L \& Friedman JE 2002 Downregulated IRS-1 and PPARgamma in obese women with gestational diabetes: relationship to FFA during pregnancy. American Journal of Physiology. Endocrinology and Metabolism 282 E522-E533.

Ciaraldi TP, Oh DK, Christiansen L, Nikoulina SE, Kong APS, Baxi S, Mudaliar S \& Henry RR 2006 Tissue-specific expression and regulation of GSK-3 in human skeletal muscle and adipose tissue. American Journal of Physiology. Endocrinology and Metabolism 291 E891-E898.

Cline GW, Johnson K, Regittnig W, Perret P, Tozzo E, Xiao L, Damico C \& Shulman GI 2002 Effects of a novel glycogen synthase kinase-3 inhibitor on insulin-stimulated glucose metabolism in Zucker diabetic fatty $(\mathrm{fa} / \mathrm{fa})$ rats. Diabetes 51 2903-2910.

Colomiere M, Permezel M, Riley C, Desoye G \& Lappas M 2009 Defective insulin signaling in placenta from pregnancies complicated by gestational diabetes mellitus. European Journal of Endocrinology 160 567-578.

Czech MP \& Corvera S 1999 Signaling mechanisms that regulate glucose transport. Journal of Biological Chemistry 274 1865-1868.

Eldar-Finkelman H \& Krebs EG 1997 Phosphorylation of insulin receptor substrate 1 by glycogen synthase kinase 3 impairs insulin action. PNAS 94 9660-9664.
Eldar-Finkelman H, Schreyer SA, Shinohara MM, LeBoeuf RC \& Krebs EG 1999 Increased glycogen synthase kinase-3 activity in diabetes- and obesity-prone C57BL/6J mice. Diabetes 48 1662-1666.

Franckhauser S, Munoz S, Elias I, Ferre T \& Bosch F 2006 Adipose overexpression of phosphoenolpyruvate carboxykinase leads to high susceptibility to diet-induced insulin resistance and obesity. Diabetes 55 273-280.

Friedman JE, Ishizuka T, Shao J, Huston L, Highman T \& Catalano P 1999 Impaired glucose transport and insulin receptor tyrosine phosphorylation in skeletal muscle from obese women with gestational diabetes. Diabetes 48 1807-1814.

Garvey WT, Maianu L, Hancock JA, Golichowski AM \& Baron A 1992 Gene expression of GLUT4 in skeletal muscle from insulin-resistant patients with obesity, IGT, GDM, and NIDDM. Diabetes 41 465-475.

Garvey WT, Maianu L, Zhu JH, Hancock JA \& Golichowski AM 1993 Multiple defects in the adipocyte glucose transport system cause cellular insulin resistance in gestational diabetes. Heterogeneity in the number and a novel abnormality in subcellular localization of GLUT4 glucose transporters. Diabetes 42 1773-1785.

Hajer GR, van Haeften TW \& Visseren FLJ 2008 Adipose tissue dysfunction in obesity, diabetes, and vascular diseases. European Heart Journal 29 2959-2971.

Hakimi P, Yang J, Casadesus G, Massillon D, Tolentino-Silva F, Nye CK, Cabrera ME, Hagen DR, Utter CB, Baghdy Y et al. 2007 Overexpression of the cytosolic form of phosphoenolpyruvate carboxykinase (GTP) in skeletal muscle repatterns energy metabolism in the mouse. Journal of Biological Chemistry 282 32844-32855.

Hashimoto N, Kido Y, Uchida T, Asahara S-I, Shigeyama Y, Matsuda T, Takeda A, Tsuchihashi D, Nishizawa A, Ogawa W et al. 2006 Ablation of PDK1 in pancreatic Î2 cells induces diabetes as a result of loss of beta cell mass. Nature Genetics 38 589-593.

Hojlund K, Staehr P, Hansen BF, Green KA, Hardie DG, Richter EA, Beck-Nielsen H \& Wojtaszewski JF 2003 Increased phosphorylation of skeletal muscle glycogen synthase at $\mathrm{NH}_{2}$-terminal sites during physiological hyperinsulinemia in type 2 diabetes. Diabetes 52 1393-1402.

Holyoak T, Sullivan SM \& Nowak T 2006 Structural insights into the mechanism of PEPCK catalysis. Biochemistry 45 8254-8263.

Kuhl C 1998 Etiology and pathogenesis of gestational diabetes. Diabetes Care 21 B19-B26.

Lappas M, Permezel M \& Rice GE 2003 N-acetyl-cysteine inhibits phospholipid metabolism, proinflammatory cytokine release, protease activity, and nuclear factor-kappaB deoxyribonucleic acid-binding activity in human fetal membranes in vitro. Journal of Clinical Endocrinology and Metabolism 88 1723-1729.

Lappas M, Permezel M \& Rice GE 2004 Release of proinflammatory cytokines and 8-isoprostane from placenta, adipose tissue, and skeletal muscle from normal pregnant women and women with gestational diabetes mellitus. Journal of Clinical Endocrinology and Metabolism 89 5627-5633.

Lappas M, Yee K, Permezel M \& Rice GE 2005 Sulfasalazine and BAY 11-7082 interfere with the nuclear factor-kappa B and I kappa B kinase pathway to regulate the release of proinflammatory cytokines from human adipose tissue and skeletal muscle in vitro. Endocrinology 146 1491-1497.

Lappas M, Yee K, Permezel M \& Rice GE 2006 Lipopolysaccharide and TNF-alpha activate the nuclear factor kappa B pathway in the human placental JEG-3 cells. Placenta 27 568-575.

Lappas M, Permezel M \& Rice GE $2007 a$ Advanced glycation endproducts mediate pro-inflammatory actions in human gestational tissues via nuclear factor-kappaB and extracellular signal-regulated kinase 1/2. Journal of Endocrinology 193 269-277.

Lappas M, Permezel M \& Rice GE $2007 b$ Mitogen-activated protein kinase proteins regulate LPS-stimulated release of pro-inflammatory cytokines and prostaglandins from human gestational tissues. Placenta 28 936-945. 
Lee H, Jang HC, Park HK, Metzger BE \& Cho NH 2008 Prevalence of type 2 diabetes among women with a previous history of gestational diabetes mellitus. Diabetes Research and Clinical Practice 81 124-129.

Livak KJ \& Schmittgen TD 2001 Analysis of relative gene expression data using real-time quantitative PCR and the 2(-Delta Delta $C(\mathrm{~T})$ ) method. Methods 25 402-408.

Metzger BE 2007 Long-term outcomes in mothers diagnosed with gestational diabetes mellitus and their offspring. Clinical Obstetrics and Gynecology $\mathbf{5 0} 972-979$.

Mingrone G, Manco M, Mora ME, Guidone C, Iaconelli A, Gniuli D, Leccesi L, Chiellini C \& Ghirlanda G 2008 Influence of maternal obesity on insulin sensitivity and secretion in offspring. Diabetes Care 31 1872-1876.

Nye CK, Hanson RW \& Kalhan SC 2008 Glyceroneogenesis is the dominant pathway for triglyceride glycerol synthesis in vivo in the rat. Journal of Biological Chemistry 283 27565-27574.

Osmond DT, King RG, Brennecke SP \& Gude NM 2001 Placental glucose transport and utilisation is altered at term in insulintreated, gestational-diabetic patients. Diabetologia 44 1133-1139.

Patel S, Doble BW, MacAulay K, Sinclair EM, Drucker DJ \& Woodgett JR 2008 Tissue-specific role of glycogen synthase kinase 3beta in glucose homeostasis and insulin action. Molecular and Cellular Biology 28 6314-6328.

Pessin JE \& Saltiel AR 2000 Signaling pathways in insulin action: molecular targets of insulin resistance. Journal of Clinical Investigation 106 165-169.

Qiu C, Vadachkoria S, Meryman L, Frederick IO \& Williams MA 2005 Maternal plasma concentrations of IGF-1, IGFBP1, and C-peptide in early pregnancy and subsequent risk of gestational diabetes mellitus. American Journal of Obstetrics and Gynecology 193 1691-1697.

Reti NG, Lappas M, Huppertz B, Riley C, Wlodek ME, Henschke P, Permezel M \& Rice GE $2007 a$ Effect of high oxygen on placental function in short-term explant cultures. Cells, Tissues, Organs 328 $607-616$.

Reti NG, Lappas M, Riley C, Wlodek ME, Permezel M, Walker S \& Rice GE $2007 b$ Why do membranes rupture at term? Evidence of increased cellular apoptosis in the supracervical fetal membranes American Journal of Obstetrics and Gynecology 196 484.e1-484.e10.
Rondinone CM, Wang LM, Lonnroth P, Wesslau C, Pierce JH \& Smith U 1997 Insulin receptor substrate (IRS) 1 is reduced and IRS-2 is the main docking protein for phosphatidylinositol 3-kinase in adipocytes from subjects with non-insulin-dependent diabetes mellitus. PNAS 94 4171-4175.

Scheck SH, Barnard RJ, Lawani LO, Youngren JF, Martin DA \& Singh R 1991 Effects of NIDDM on the glucose transport system in human skeletal muscle. Diabetes Research 16 111-119.

Sebire NJ, Jolly M, Harris JP, Wadsworth J, Joffe M, Beard RW, Regan L \& Robinson S 2001 Maternal obesity and pregnancy outcome: a study of 287,213 pregnancies in London. International Journal of Obesity and Related Metabolic Disorders 25 1175-1182.

Sivan E, Homko CJ, Whittaker PG, Reece EA, Chen X \& Boden G 1998 Free fatty acids and insulin resistance during pregnancy. Journal of Clinical Endocrinology and Metabolism 83 2338-2342.

Sivan E, Homko CJ, Chen X, Reece EA \& Boden G 1999 Effect of insulin on fat metabolism during and after normal pregnancy. Diabetes 48 834-838.

Stump CS, Henriksen EJ, Wei Y \& Sowers JR 2006 The metabolic syndrome: role of skeletal muscle metabolism. Annals of Medicine $\mathbf{3 8}$ 389-402.

Tomazic M 2002 Comparison of alterations in insulin signalling pathway in adipocytes from type II diabetic pregnant women with gestational diabetes mellitus. Diabetologia 451744.

Xiang AH, Peters RK, Trigo E, Kjos SL, Lee WP \& Buchanan TA 1999 Multiple metabolic defects during late pregnancy in women at high risk for type 2 diabetes. Diabetes 48 848-854.

Yamada T, Katagiri H, Asano T, Tsuru M, Inukai K, Ono H, Kodama T, Kikuchi M \& Oka Y 2002 Role of PDK1 in insulinsignaling pathway for glucose metabolism in 3T3-L1 adipocytes. American Journal of Physiology. Endocrinology and Metabolism 282 E1385-E1394.

Received in final form 6 October 2009

Accepted 1 December 2009

Made available online as an Accepted Preprint 2 December 2009 